Reprinted from the Journal of Production Agriculture

Volume 3, no. 2, April-June 1990

677 South Segoe Rd., Madison, W1 59711 USA

\title{
Economic Weed Control in High Plains Cotton
}

Don E. Ethridge, R.Terry Ervin, Clay M. Hamilton, J. Wayne Keeling, and John R. Abernathy 


\title{
Economic Weed Control in High Plains Cotton
}

\author{
Don E. Ethridge, R.Terry Ervin, Clay M. Hamilton, \\ J. Wayne Keeling, and John R. Abernathy*
}

This study considered factors that affect the weed control efficacy and profitability of several major herbicides used in cotton (Gossypium hirsutum L.) on the High Plains. The herbicides were Caparol ${ }^{1}$ (N,N'-bis $\{1-$-methylethyl $\}$-6-(methylthio)1,3,5-triazine-2,4-diamine), Dual (2-chloro-N-\{2-ethyl-6-methylphenyl $\}-N-\{2-m e t h o x y-1-m e t h y l e t h y l\}$ acetamide), Prowl (N\{1-ethylpropyl\}-3,4-dimethyl-2,6-dinitrobenzenamine), Sancap (6-\{ethylthio\}-N,N'bis-\{1-methylethyl\}-1,3,5-triazine-2,4-diamine), and Treflan (2,6-di-nitro-N,N-dipropy\}-4-\{trifluoromethyl \}enzenamine). Results indicate that: (i) little additional yield is necessary to justify the use of herbicides; (ii) conditions present when herbicides are applied and crops planted affect herbicide effectiveness (generally, higher temperatures at application and planting dates result in better control and/or higher additional yields); and (iii) in some cases farmers should reduce the manufacturers' recommended rates of herbicide application to increase their profit.

$\mathrm{F}^{\circ}$ OR APPROXMMATELY four million row-crop acres in the Southwest USA, weed conrol cost producers $\$ 122.7$ million in 1983 (Frans and Chandler, 1989). Ten species cause approximately $75 \%$ of cotton losses from weeds. Six of the 10 commonly found in the High Plains of Texas include morningglory (Ipomoea spp.), common cocklebur (Xanthium pensylvanicum Wallr.), pigweed (Amaranthus spp.), Russian thistle (Salasola kali L.), johnsongrass (Sorghum halepense L.), and silverleaf nightshade (Solanum elaeagnifolium Cav.) (Holm et al., 1977). Competition from these results in yield reduction, decreased crop quality, increased costs due to control efforts, and reduction in irrigation and water management efficiency. As foreign matter is increased in the field and included with the harvested crop the grade is lowered. As grade decreases the price also decreases; e.g., if trash content causes the grade to decrease from a grade of 42 to 52 , this could result in a decrease in price of 3 cents per pound in today's market.

Cotton production in the U.S. without herbicides could result in a $32 \%$ yield reduction from weed competition (Abernathy, 1981). While total weed control can be achieved, economic logic suggests that this level of weed control is rarely desirable. Rather than total weed control, optimum control must balance the cost of weed control per acre with the potential yield increase and other benefits associated with weed control (Frans and Chan-

D.E. Ethridge and R.T. Ervin, Dep. of Agric, Econ., Texas Tech University, Lubbock, Texas 79409; C.M. Hamilton, Foreign Agricultural Service, USDA, Washington, DC 20250; J.W. Keeling and J.R. Abernathy, Texas Agric. Exp. Stn., Lubbock, TX 79401. This is publication no. T-1-295 of the Texas Tech University College of Agricultural Sciences. This project was supported by the Texas Agric. Exp. Stn. and Texas Tech University. Received May 1989.

Published in J. Prod. Agric. 3:246-252 (1990). dler, 1989). Economically rational weed control can be described as the range of control where herbicide use is profitable. The lower limit of this range is called the economic threshold level. This weed control will result in positive net returns (value of additional income minus cost of weed control). Ideally, a farmer would produce at the point where the difference between the cost of control and the dollars returned is greatest (maximum profit).

The problem arises in determining that level of weed control which is optimum. To locate the most profitable level of weed control for those weeds adversely affecting cotton, the relationship between weed control and yield must be understood. This relationship, in turn, is affected by a variety of factors such as herbicide treatment, weather, and level of weed population. Once these relationships are determined, a more effective weed control program is possible. The objective of this study was to determine the economically efficient levels of weed control in High Plains cotton production.

\section{METHODS AND PROCEDURES}

Data for the analysis were from cotton herbicide use trials at the Texas Agricultural Experiment Station in Lubbock County from 1973 through 1985 . This data set contained experiments on comparisons of the control levels for different herbicides, evaluations of rates for a single herbicide, and effects of different herbicides on specific weeds. The locations, application methods, and other conditions varied from experiment to experiment. The control yield-pounds of cotton lint harvested from untreated plots-was included for each trial. Selected preplant and pre-emergence herbicides used on cotton in the High Plains were considered for this study: Caparol, Dual, Prowl, Sancap, and Treflan. ${ }^{1}$ Each herbicide was evaluated separately. Binary indicator (dummy) variables were used to control for the effect of qualitative variables: type of experiment, site, cotton variety, herbicide incorporation method, soil type, irrigation method, and weed type. Rainfall (RAIN) and irrigation (IRRG) water for the growing season (January through September) were added to the data set. The sum of the variables RAIN and IRRG created the variable WATER.

\section{Development of the Model}

The yield response function was specified in terms of additional yield attributable to herbicide use, AYD (yield minus control yield). A primary variable in AYD is weed

\footnotetext{
${ }^{1}$ Product names are included for informational purposes only and do not represent an endorsement of the product of a specific manufacturer. No implication is intended that formulations containing the same active chemical are not equally effective.
} 
control (CON); greater CON results in greater AYD. However, some factors such as water and soil type affect both CON and AYD. That is AYD and CON are affected independently by some variables and simultaneously by others. A two-equation model was formulated with seed control as an explanatory variable in the yield model. The resulting equations were:

AYD $=f(C O N$, PDT, WATER, SOT, COT, YR $)$

$\mathrm{CON}=\mathrm{g}(\mathrm{RAT}, \mathrm{ADT}, \mathrm{TDY}, \mathrm{ATP}, \mathrm{STP}, \mathrm{SDT}$,

ARN, WATER, EXP, SOT, WED, INC, YR)

where

AYD $=$ additional cotton yield (lb lint per acre);

CON = control of weed infestation (\%);

RAT $=$ herbicide application rate (lb a.i. per acre);

ADT $=$ herbicide application date (Julian calendar);

TDY = time delay of herbicide incorporation into the soil from date of application (d);

PDT = date cotton was planted (Julian calendar);

ATP $=$ air temperature at time of herbicide application ( $\left.{ }^{\circ} \mathrm{F}\right)$;

STP = soil surface temperature at time of herbicide application ( $\left.{ }^{\circ} \mathrm{F}\right)$;

SDT $=$ soil temperature at 4 in. depth at time of herbicide application $\left({ }^{\circ} \mathrm{F}\right)$;

ARN = period from application of herbicide to first rainfall (d);

WATER = rainfall plus irrigation (January through September) of water (acre in.);

EXP = type of experiment from which data were generated, a system of dummy variables; (EXP-1 = 1 for combination screen, EXP-2 $=1$ for delayed incorporation, EXP-3 = 1 for pre-emergence screen, EXP-4 = 1 for pre-plant herbicide, EXP-5 = 1 for preplant incorporation screen, EXP-6 = 1 for date of application, EXP-7 = 1 for method of incorporation, EXP-8 = 1 for dual effect on cotton, EXP-9 $=1$ for pre-plant screen, EXP-10 = 1 for cotton-min-till, EXP-11 for weed control, EXP-12 = 1 for no reported experiment, EXP-13 = 1 for pre-emergence, EXP-14 = 1 for preplant, and EXP-15 = 1 for preplant incorporation. If EXP-1 = EXP-2 = EXP-3 = $\ldots=\mathrm{EXP}-15=0$, then the experiment is designated as the base dummy variable which is screening trial.);

SOT = soil type, a system of dummy variables; (SOT-1 = 1 for Amarillo fine sandy loam, SOT-2 $=1$ for Amarillo sandy clay loam (fine-loamy, mixed, thermic Aridic Paleustoll), SOT-3 $=1$ for Pullman silty clay loam (fine, mixed, thermic Torrertic Paleustoll), SOT $-4=1$ for Pullman clay loam, SOT $-5=1$ for sandy, and SOT $-6=$ 1 for no reported soil type. If SOT-1 $=$ SOT $-2=$ SOT $-3=\ldots=$ SOT $-6=0$, then the soil type is designated as the base dummy variable which is Amarillo sandy clay loam.);

WED = type of weed treated during trials, a system of dummy variables; (WED-1 = 1 for pigweed, WED-2 = 1 for grain sorghum [Sorghum bicolor (L.) Moench.], WED-3 = 1 for morningglory, WED-4 = 1 for prairie sunflower (Helianthus petiolaris Nut.), WED-5 = 1 for Venice mallow (Hibiscus trionum L.), WED-6 = 1 for millet (Setaria pennisitum glaucum) residue, WED-7 = 1 for yellow nutsedge (Cyperus esculentus L.), WED-8 $=1$ for panicum (Panicum texanum Buckl.), and WED-9 = 1 for volunteer wheat (Triticum aestivum L.). If WED-1 = WED-2 = WED-3 = ... = WED-9 $=0$, then the weed type is designated as the base dummy variable which is johnsongrass.);

INC = method of herbicide incorporation, a system

of dummy variables; (INC-1 $=1$ for preplant incorporated rolling cultivator, INC-2 $=1$ for pre-emergence, INC-3 $=1$ preplant incorporated, INC-4 = 1 no reported in corporation, INC-5 = 1 pre-emergence screen, INC- $6=1$ post topical, INC-7 $=1$ preplant incorporated lister, INC-8 $=1$ preplant, INC-9 $=1$ preplant incorporated bedder, and INC-10 $=1$ post directed. If INC-1 = INC-2 $=$ INC-3 $=\ldots=$ INC-10 $=0$, then the incorporation method is designated as the base dummy variable which is preplant incorporated disk.);

COT $=$ variety of cotton used for a trial, a system of dummy variables; (COT-1 $=1$ for 'Dunn $56 \mathrm{C}$ ', COT-2 = 1 for 'Dunn 118', COT-3 $=1$ for 'Sp 21', COT $4=1$ for 'Paymaster 101', COT $-5=1$ for 'GSA 71', COT-6 = 1 for 'Paymaster 26', COT-7 = 1 for 'Paymaster', COT-8 = 1 for 'Tamcot', COT-9 $=1$ 'Paymaster 404', COT-10 = 1 for 'Lankart 57', COT-11 = 1 for no reported cotton variety, and COT-12 $=1$ for 'Paymaster $18^{\prime}$. If COT $-1=$ COT $-2=$ COT -3 $=\ldots=$ COT $-12=0$, then the cotton type is designated as the base dummy variable which is 'Dunn 119'.);

$\mathrm{YR}=$ year the experiment was conducted, a system of dummy variables representing years from 1973 to 1985.

Three variables, RAT, WATER, and PDT were hypothesized to result in nonlinear relationships; they are expected to increase AYD or CON, but at a decreasing rate; and there may be a point after which additional units would result in lowered yield or control. In the model, RAT, WATER, and PDT were expressed alternatively in quadratic or logarithmic form to capture the diminishing marginal returns associated with these variables. For some of the herbicides, CON and AYD were best represented 
as log-log models and in some cases the variables PDT, RAT, and ADT were logged individually (semilogarithmic). CON and WATER were combined (CON $x$ WATER) as an interaction term in several models to capture their effects on AYD.

Assuming the herbicide is applied early enough at the beginning of the production cycle to restrict weed infestations, the coefficient of ADT should have a positive sign because it controls weeds for a longer period. Because herbicides often are activated by moisture and incorporated into the soil, coefficients of TDY and ARN were expected to have negative signs. Coefficients of ATP, STP, and SDT could have positive or negative signs. The coefficient signs for YR could be positive or negative, depending on the nature of the trend, if present. Over wide ranges of values, these variables may be expected to have non-linear relationships with CON or AYD. The range of available data for these variables, however, did not deviate substantially from expeced or recommended levels; thus, the relationships may be linear over the range of data. Signs for the dummy variable coefficients could not be anticipated in most cases.

\section{Estimation Procedures}

Correlation coefficients were evaluated to identify possible multicollinearity problems. A high level of correlation was found among several variables. Some variables, particularly dummy variables, were perfectly correlated. For example, in the data set for Caparol, cotton variety was perfectly correlated with the site of the experiment. Starting with the dummy variables and those variables that were least important theoretically, variables were dropped to allow the model to be estimated. The STEPWISE procedure of SAS was used (SAS Institute, Inc., 1985) to identify the relationships for AYD and CON that best satisfied the conceptual model. Statistical criteria were selected as a result of the use of the STEPWISE procedure. In the STEPWISE analysis, various combinations of the exogenous variables were analyzed using generalized least squares. Within the STEPWISE procedure, the Maximum R-square method was used to select the variable combinations. This was selected because, when compared to the Backward and Forward methods, the Maximum R-square method gave the most consistent and comprehensive solutions to the model.

The equations for CON and AYD were anticipated to be interrelated, i.e., the error terms from the two estimated relationships may be correlated. Although CON and AYD are related, it was not known to what degree they affect each other. To evaluate this relationship, the models were estimated using seemingly unrelated regression (SUR) procedures. By using SUR each equation was first estimated independently using the method of ordinary least squares (OLS). The error terms from this estimation were used to create a variance-covariance matrix, of which the primary diagonal represents the constant variance of error terms for each equation. The offdiagonal elements represent the covariance of error terms across equations. This matrix was then used to adjust both models and they were re-estimated. If the covari- ances of such a matrix are equal to zero, then this estimation procedure is identical to OLS. Otherwise, SUR estimates provide a more accurate set of results (Johnston, 1972).

\section{Economic Optimization Procedure}

The yield response models provided part of the necessary information with which to evaluate economically optimum weed control decisions. The greatest profit will be achieved when the difference between the revenue received for the end product (AYD) and the total cost of production for the end product is largest. For this to occur, the system must be optimized with respect to each decision variable simultaneously. The decision variables in this study included RAT, WATER, SDT, and ADT. Optimization with respect to the decision variables required that complex derivatives be developed. Thus, the computer software program EUREKA (Borland International, 1987) was used to evaluate derivatives and definite integrals. The AYD and CON equations were entered into the program and constraints imposed to insure that optimum solutions fell within the range of known input-output values rather than becoming extrapolations beyond the range of experience. Solutions for maximum weed control, maximum additional yield, and maximum profit (optimum weed control) were obtained for each of the five herbicides.

To solve for optimum herbicide use it was necessary to develop a profit function for the models. The profit function associated with herbicide use was:

$$
\begin{aligned}
\text { Profit } & =(\text { AYD } \times \$ 0.55)-(\text { RAT } \times \text { cost of herbicide } \\
& + \text { application cost })-(\text { IRRG } \times \$ 4.91)
\end{aligned}
$$

where AYD and RAT are as previously defined, and IRRG represents irrigation (i.e., water minus rainfall) in acre-inches. A cotton price of $\$ 0.55 / \mathrm{lb}$ of lint was used as representative. The cost of herbicide ranged from $\$ 5.25$ to $\$ 6 / \mathrm{lb}$ a.i. Fixed costs for herbicide application were $\$ 2$ acre plus $\$ 4$ /acre for incorporation; only Treflan and Prowl require incorporation (Texas Agricultural Extension Service, 1987). The cost of IRRG included averaged costs of labor, fuel, and equipment for both sprinkler and furrow systems, and was calculated to be $\$ 4.91$ acre-in. of water (Texas Agricultural Extension Service, 1987).

Where variables necessary for the profit function (e.g., RAT) were not significant in the CON and AYD models, the low end of the data set range was used. In a case like this, the herbicide was important in controlling weeds, but there was no difference in CON or AYD among rates. Thus, significance was not found in the range of herbjcide rates applied; this might have been due to a relatively small variation in the range of rates applied. The lowest rate (and the lowest cost) is the most profitable rate to use.

To make solutions meaningful for production decisions, variables that are not under the control of the farmer were held constant. These variables included YR, EXP, and SOT. YR was held constant at 1985, the most recent period in the data set. The amount of rainfall was held 
Table 1. Statistical model results for Caparol.

\begin{tabular}{|c|c|c|c|c|}
\hline Variable $†$ & \multicolumn{2}{|l|}{ Estimate } & t-ratio & Prob $>[t]$ \\
\hline \multicolumn{5}{|c|}{ Control equation (ln CON) } \\
\hline $\begin{array}{l}\text { Intercept } \\
\text { RAT } \\
\text { SDT } \\
\text { ARN } \\
\text { EXP-3 } \\
\text { EXP-13 } \\
\text { SOT-2 } \\
\text { WED-2 } \\
\text { SIT-5 }\end{array}$ & $\begin{array}{r}1.8840 \\
0.3490 \\
0.0304 \\
-0.0590 \\
-1.1088 \\
0.2080 \\
0.9598 \\
-2.1889 \\
0.4396\end{array}$ & & $\begin{array}{l}2016 \\
2354 \\
5757 \\
2912 \\
3135 \\
3144 \\
400 \\
423 \\
4969\end{array}$ & $\begin{array}{l}0.0390 \\
0.0364 \\
0.0176 \\
0.0035 \\
0.0100 \\
0.0693 \\
0.0002 \\
0.0001 \\
0.0867\end{array}$ \\
\hline \multicolumn{5}{|c|}{ Additional yield equation (ln AYD) } \\
\hline $\begin{array}{l}\text { Intercept } \\
\text { CON } \\
\text { SOT-1 } \\
\text { COT-5 } \\
\text { EXP-5 } \\
\text { EXP-11 }\end{array}$ & $\begin{array}{r}5.3604 \\
0.0084 \\
-0.2989 \\
0.1128 \\
-0.5399 \\
-0.2160\end{array}$ & & $\begin{array}{l}767 \\
1875 \\
6634 \\
0938 \\
2032 \\
1801\end{array}$ & $\begin{array}{l}0.0001 \\
0.0001 \\
0.0001 \\
0.0470 \\
0.0003 \\
0.0393\end{array}$ \\
\hline $\mathrm{n}=30$ & \multicolumn{3}{|c|}{ Prob $>F=0.0001$} & $\mathrm{di} \mathrm{R}^{2}=0.8454$ \\
\hline \multirow{2}{*}{\multicolumn{5}{|c|}{$\begin{array}{l}\text { Tariables having a number appended to the right are: EXP-3, 5, } 11 \text {, and } \\
13 \text { representing pre-emergence screen, preplant incorporation screen, weed } \\
\text { control, and pre-emergence tests, respectively; SO'T-1 and } 2 \text { represent- } \\
\text { ing fine sandy loam and sandy clay loam soils, respectively; WED-2 } \\
\text { representing grain sorghum as a weed; SI'T-5 representing Big Spring, } \\
\text { TX, as an experiment site; COT-5 representing the cotton variety GSA 71. } \\
\text { Table } 2 \text {. Solutions for maximum control, adiditional yield, and } \\
\text { profit using Caparol. }\end{array}$}} \\
\hline & & & & \\
\hline \multirow[b]{2}{*}{ Variable } & \multirow[b]{2}{*}{$\begin{array}{c}\text { Maximum } \\
\text { CON }\end{array}$} & \multirow[b]{2}{*}{$\begin{array}{c}\text { Maximum } \\
\text { AYD }\end{array}$} & \multicolumn{2}{|c|}{ Maximum profit } \\
\hline & & & $\begin{array}{l}\text { Without } \\
\text { IRRG }\end{array}$ & $\begin{array}{l}\text { With } \\
\text { IRRG }\end{array}$ \\
\hline Cor & 100 & 100 & 100 & 100 \\
\hline AYD & & 273 & 273 & \\
\hline RAT & 2.4 & 2.4 & 0.75 & 0.75 \\
\hline ARN & 1 & I & 1 & \\
\hline $\begin{array}{l}\text { SDT } \\
\text { IRRG }\end{array}$ & 65 & 65 & 84 & 84 \\
\hline Profit/acre & & $\$ 130.13$ & $\$ 151.87$ & $\$ 151.87$ \\
\hline Confidence level & $87.80 \%$ & $95.00 \%$ & $69.30 \%$ & $69.60 \%$ \\
\hline
\end{tabular}

constant at 14 acre-in. of water, the 13-yr average. All dummy variables were initially held constant at zero representing the base values. Once these constant base values were determined, they were individually changed to observe their individual effect on the optimal solution for the values of RAT, CON, AYD, and IRRG. Variables other than dummy variables were varied by $23 \%$ from their baseline values.

Using the baseline values, the profit functions for the various herbicides were evaluated for the breakeven levels of AYD at different cotton prices and herbicide costs. The level of AYD required for weed control to be economically feasible was the break-even level sought. As the price of cotton or cost of herbicide changes, the AYD required to justify using the herbicide changes. The breakeven level for AYD was derived by setting the profit function equal to zero and solving for the price of cotton (or herbicide cost) while holding all other elements constant. A spreadsheet program was used to solve a series of these equations.

\section{RESULTS AND DISCUSSION}

Because the tables necessary to indicate preliminary procedural results for all five herbicides are numerous, statistical results obtained through simultaneously regress- ing the two related equations of control (CON) and additional yield (AYD) are presented and discussed for Caparol only. Caparol is selected because it is one of the most commonly used herbicides in the region. Solutions for maximum control, maximum additional yield, and maximum profit using Caparol are then presented and discussed. Documentation of results for the remaining herbicides can be found in Hamilton (1988). Following the discussion of the preliminary results for Caparol, the optimal solutions for all herbicides (levels of control, additional yield, and profit) considered in this study are presented.

Regression results for Caparol are listed in Table 1. Variables influencing effectiveness of Caparol are listed in the first column. Coefficients for each variable estimated through statistical analysis are listed in the second column, followed by the respective t-ratios and p-values in columns 3 and 4 , respectively. The p-value represents the probability of observing a t-ratio as large as was estimated if the null hypothesis (i.e., coefficient is equal to zero) were true. Results indicate that the exogenous variables are nonlinearly related to control. Thus, both CON and $A X D$ were converted to natural logarithms. In the control equation, three quantitative variables (RAT, SDT, and ARN) and five qualitative (dummy) variables were statistically significant. RAT proved to be important in determining the percent control. Grain sorghum (WED-2) acting as a weed had a significant negative affect, lowering control by $38 \%$ when present. Fine sandy loam soil (SOT-1) also lowered yield, but cotton variety GSA 71 (COT-5) increased yield by $42 \mathrm{lb}$.

A set of equations for each herbicide was solved for maximum levels of control, additional yield, and profit with and without irrigation. Profit maximization results for Caparol are listed in Table 2. Although maximum CON and AYD required a RAT of $2.4 \mathrm{lb}$, the herbicide application rate (RAT) was lowered to $0.75 \mathrm{lb}$ for maximum profit. No additional levels of water over $14 \mathrm{in}$. of rainfall came into the optimal solution when an irrigation cost was included. Additional yield (AYD) expected from this level of inputs was $273 \mathrm{lb}$ of lint.

Changing the values of PDT, STP, cost of irrigation, and rainfall in the optimal solutions provided the means to evaluate the impacts of variations in those variables on the optimal solution. Likewise, changing the value of each dummy variable from zero to one facilitated the examination of the effect of each variable falling within the optimum solution. Results derived by varying inputs in the Caparol optimum solutions are listed in Table 3 . The base value for the soil temperature at 4 in. depth was $84^{\circ} \mathrm{F}$. This was decreased by $20 \%$ to $67^{\circ} \mathrm{F}$, to represent effects of applying Caparol at lower soil temperatures. The AYD and CON remained the same but a higher rate of herbicide application, $2.2 \mathrm{lb} /$ acre a.i., was required to keep the same level of production at this lower temperature. The increased expense for this input lowered the profit level to $\$ 135.14$. When the period from application of herbicide to first rainfall (ARN) was changed from its base value of $1 \mathrm{~d}$ delay to $3 \mathrm{~d}$, the optimum level of RAT rose from 0.91 to $1.01 \mathrm{lb} /$ acre while profit correspondingly droped by $\$ 2.03$. 
Table 3. Optimal solutions for Caparol with selected variables individually changed from baseline conditions. $\dagger$

\begin{tabular}{|c|c|c|c|c|c|c|c|c|c|c|c|c|}
\hline \multirow[b]{2}{*}{ Vuriable } & \multirow[b]{2}{*}{$\begin{array}{l}\text { Base } \\
\text { value }\end{array}$} & \multicolumn{11}{|c|}{ Modified condition } \\
\hline & & $\begin{array}{l}\text { SDT, } \\
67{ }^{\circ} \mathrm{F}\end{array}$ & $\begin{array}{c}\text { ARN, } \\
3 \mathrm{~d}\end{array}$ & EXP-3 & EXP.13 & SOT.2 & WED-2 & SIT-5 & SOT-1 & COT-5 & EXP.5 & EXP.11 \\
\hline Profit & $\$ 143.91$ & $\$ 135.14$ & $\$ 141.88$ & $\$ 60.82$ & $\$ 146.89$ & $\$ 146.90$ & $\$ 12.64$ & $\$ 146.89$ & \$76.43 & $\$ 175.06$ & $\$ 35.27$ & $\$ 93.33$ \\
\hline
\end{tabular}

$\dagger$ Variables having a number appended to the right are: EXP-3, 5, 11, and 13 representing pre-emergence screen, preplant incorporation screen, weed control, and pre-emergence tests, respectively; SOT-1 and 2 representing sandy loam and sandy clay loam soils, respectively; WED-2 representing grain sorghum as a weed; SIT-5 representing the Big Spring, TX, experiment site; COT-5 representing the cotton variety GSA 71.

Table 4. Optimal solutions for Dual with selected variables changed individually. $\dagger$

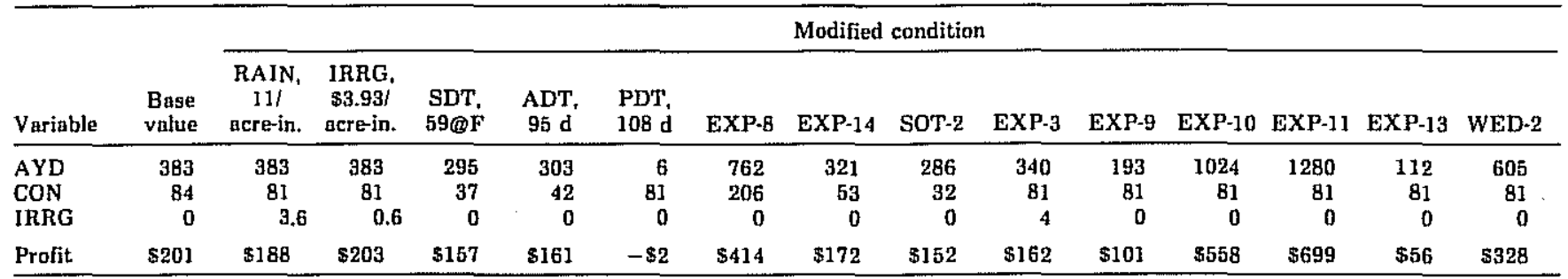

† Variables having a number appended to the right are: EXP-3, 8, 9, 10, 11, and 14 representing pre-emergence screen, dual effect on cotton, preplant screen, cotton-min-till, weed control, and preplant,respectively; SOT-2 repregenting fine sandy clay loam soils; WED-2 representing grain sorghum as a weed.

Table 5. Optimal solutions for the Prowl AYD model with selected variables changed individually. $\dagger$

\begin{tabular}{|c|c|c|c|c|c|c|c|c|c|}
\hline \multirow[b]{2}{*}{ Variable } & \multirow[b]{2}{*}{$\begin{array}{l}\text { Base } \\
\text { values }\end{array}$} & \multicolumn{8}{|c|}{ Modified condition } \\
\hline & & $\begin{array}{l}\text { RAIN, } \\
\text { 11/acre-in }\end{array}$ & $\begin{array}{l}\text { IRRG, } \\
\text { \$3.93/acre-in. }\end{array}$ & $\begin{array}{l}\text { PDT, } \\
110 \mathrm{~d}\end{array}$ & EXP-1 & EXP-9 & EXP-10 & COT.2 & INC-4 \\
\hline AYD & 187 & 170 & 187 & -188 & 273 & 83 & 325 & -1 & 247 \\
\hline JRRG & 0 & 0 & 0 & 0 & 0 & 0 & 0 & 0 & 0 \\
\hline Profit & $\$ 95$ & $\$ 85$ & $\$ 95$ & $-\$ 112$ & $\$ 141$ & $\$ 37$ & $\$ 170$ & -59 & $\$ 127$ \\
\hline
\end{tabular}

$\dagger$ Variables having a number appended to the right are: EXP.1, 9, and 10, representing combination screen, preplant screen, and cotton-min-til, respectively; COT-2 representing cotton variety Dunn 118; INC-4 representing preplant incorporated.

Table 6. Optimal solutions for Sancap with selected variables changed individually. $\dagger$

\begin{tabular}{|c|c|c|c|c|c|c|c|}
\hline Variable & $\begin{array}{c}\text { Base } \\
\text { balues }\end{array}$ & \multicolumn{6}{|c|}{ Modified condition } \\
\hline Profit & $\$ 178$ & 141 & $\$ 178$ & $\$ 140$ & $-\$ 13$ & $\$ 178$ & $\$ 178$ \\
\hline
\end{tabular}

$\dagger$ Variables having a number appended to the right are EXP-4 and 11, representing preplant herbicide and weed control, respectively.

Table 7. Optimal solutions for Treflan with selected variables changed individually. $\dagger$

\begin{tabular}{|c|c|c|c|c|c|c|c|c|}
\hline \multirow[b]{2}{*}{ Variable } & \multirow[b]{2}{*}{$\begin{array}{c}\text { Base } \\
\text { values }\end{array}$} & \multicolumn{7}{|c|}{ Modified condition } \\
\hline & & $\begin{array}{l}\text { RAIN, } \\
\text { 11/acre-in. }\end{array}$ & $\begin{array}{c}\text { IRRG, } \\
\text { \$3.93/acre-in. }\end{array}$ & $\begin{array}{l}\text { ADT, } \\
157 \mathrm{~d}\end{array}$ & INC-10 & EXP.11 & EXP-15 & INC-2 \\
\hline Profit & $\$ 180$ & $\$ 178$ & $\$ 180$ & $\$ 180$ & $\$ 149$ & $\$ 117$ & $\$ 180$ & $\$ 113$ \\
\hline
\end{tabular}

† Variables having a number appended to the right are: EXP.11 and 15, representing weed control and preplant incorporation, respectively; and INC-2 and 10 representing preplant incorp. rolling cultivator, and preplant incorp. Bedder, respectively. 
The fact that dummy variables represent only the presence or absence of a condition and not the degree to which that condition is present, requires that caution be used when evaluating optimal model shifts when the base value of each dummy variable is changed from zero to one. Changing the value of the dummy variable for the pre-emergence screen experiment (EXP-3) caused the optimum control to drop to $59 \%$ and RAT increased to $2.4 \mathrm{lb} /$ acre. Changing the base value for the preemergence experiment (EXP-13), sandy clay loam soil (SOT-2), and the Big Spring site (SIT-5) caused the optimum RAT to decrease to the lower limit of the range of data $(0.25 \mathrm{lb} / \mathrm{acre})$. This indicates that Caparol works more efficiently with sandy clay loam than with other soil types and that less herbicide is needed. Consequently, inputs which have a cost associated with them are most effectively used at the lower limit of range constraints in controlling this weed.

With fine sandy loam soil (SOT-1), cotton variety GSA 71 (COT-5), preplant incorporation screen experiment (EXP-5), and cotton minimum tillage experiment (EXP-11), optimum solutions included RAT values of 0.75 and $\mathrm{CON}$ at $100 \%$. Although these variables were factors only in the AYD model and do not directly affect control percentages, they do have varying effects on AYD. This indicates that less cultivation with minimum tillage (EXP-11) lowers AYD and profit. Tables containing information for Dual, Prowl, Sancap, and Treflan similar to that for Caparol contained in Table 3 are provided in Tables 4 through 7 .

The average pounds of additional cotton yield for each additional percent of control achieved at the median levels of control for the five herbicides considered in this study was $2.1 \mathrm{lb}$. The percent of control was optimized at varying levels for each herbicide, ranging from $37 \%$ for Treflan to $100 \%$ for Caparol and Prowl, depending on the conditions present. Based on the current price of cotton and costs of herbicide, additional yield of 10 to $20 \mathrm{lb} /$ acre will pay for the cost of the weed control.

\section{Break-Even Values}

As yield increases as a result of weed control, producers may be justified in investing additional capital into the use of herbicides. However, because herbicide costs fluctuate, producers may be unsure of what to expect in returns for this investment. One pound per acre increases of AYD corresponding to the amount of return available to pay for each type of herbicide weed control are represented in Table 8. The price of cotton (Py) was held constant at $\$ 0.55 / \mathrm{lb}$. The fixed cost was set at $\$ 6 /$ acre for herbicides that had to be incorporated (Prowl and Treflan) and \$2/acre for Caparol, Dual, and Sancap. The rate used for each herbicide was the amount found to maximize profit. Other input costs were assumed constant while the cost of herbicide was not allowed to exceed $\$ 10 / \mathrm{lb}$ a.i. for this table.

It was found that, at very low levels of AYD, the use of herbicides was not economically feasible. This is represented by negative values for herbicide prices $(\mathrm{Px})$ (e.g., $10 \mathrm{lb}$ of additional yield with Caparol would sup-
Table 8. Maximum feasible herbicide prices $(\mathrm{Px})$ as affected by additional pounds of cotton produced (AYD).

\begin{tabular}{|c|c|c|c|c|c|c|c|c|c|}
\hline \multicolumn{2}{|c|}{ Caparol } & \multicolumn{2}{|c|}{ Dual } & \multicolumn{2}{|c|}{ Prowl } & \multicolumn{2}{|c|}{ Sancap } & \multicolumn{2}{|c|}{ Treflan } \\
\hline AYD & $\mathbf{P x}$ & AYD & Px & AYD & $P x$ & AYD & $P x$ & AYD & $P_{x}$ \\
\hline & $\mathbf{s}$ & & $s$ & & $\$$ & & $s$ & & $\$$ \\
\hline $\begin{array}{r}1 \\
2 \\
3 \\
4 \\
5 \\
6 \\
7 \\
8 \\
9 \\
10 \\
11 \\
12 \\
13 \\
14 \\
15 \\
16 \\
17\end{array}$ & $\begin{array}{r}-1.99 \\
-1.20 \\
-0.47 \\
0.27 \\
1.00 \\
1.73 \\
2.47 \\
3.20 \\
3.93 \\
4.67 \\
5.40 \\
6.13 \\
6.87 \\
7.60 \\
8.33 \\
9.07 \\
9.80\end{array}$ & $\begin{array}{r}1 \\
2 \\
3 \\
4 \\
5 \\
6 \\
7 \\
8 \\
9 \\
10 \\
11 \\
12\end{array}$ & $\begin{array}{r}-2.90 \\
-1.80 \\
-0.70 \\
0.40 \\
1.50 \\
2.60 \\
3.71 \\
4.80 \\
5.90 \\
7.00 \\
8.10 \\
9.20\end{array}$ & $\begin{array}{r}1 \\
2 \\
3 \\
4 \\
5 \\
6 \\
7 \\
8 \\
9 \\
10 \\
11 \\
12 \\
13 \\
14 \\
15 \\
16 \\
17 \\
18 \\
19 \\
20\end{array}$ & $\begin{array}{r}-10.90 \\
-9.80 \\
-8.70 \\
-7.60 \\
-6.50 \\
-5.40 \\
-4.30 \\
-3.20 \\
-2.10 \\
-1.00 \\
0.10 \\
1.20 \\
2.30 \\
3.40 \\
4.50 \\
5.60 \\
6.70 \\
7.80 \\
8.90 \\
10.00\end{array}$ & $\begin{array}{l}1 \\
2 \\
3 \\
4 \\
5 \\
6 \\
7 \\
8 \\
9 \\
10 \\
11 \\
12 \\
13 \\
14 \\
15 \\
16 \\
17 \\
18 \\
19 \\
20 \\
21 \\
22 \\
23 \\
24 \\
25\end{array}$ & $\begin{array}{r}-1.21 \\
-0.75 \\
-0.29 \\
0.17 \\
0.93 \\
1.08 \\
1.54 \\
2.00 \\
2.46 \\
2.92 \\
3.38 \\
3.83 \\
4.29 \\
4.75 \\
5.21 \\
5.67 \\
6.13 \\
6.58 \\
7.04 \\
7.50 \\
7.96 \\
8.42 \\
8.88 \\
9.33 \\
9.79\end{array}$ & $\begin{array}{r}1 \\
2 \\
3 \\
4 \\
5 \\
6 \\
7 \\
8 \\
9 \\
10 \\
11 \\
12 \\
13 \\
14 \\
15 \\
16 \\
17 \\
18 \\
19\end{array}$ & $\begin{array}{r}-12.11 \\
-10.89 \\
-9.67 \\
-8.44 \\
-7.22 \\
-6.00 \\
-4.78 \\
-3.56 \\
-2.33 \\
-1.11 \\
0.11 \\
1.33 \\
2.56 \\
3.78 \\
5.00 \\
6.22 \\
7.44 \\
8.67 \\
9.89\end{array}$ \\
\hline
\end{tabular}

Table 9. Prices of cotton necessary (Py) to justify herbicide application as affected by additional pounds of cotton produced (ÂYD).

\begin{tabular}{|c|c|c|c|c|c|c|c|c|c|}
\hline \multicolumn{2}{|c|}{ Ceparol } & \multicolumn{2}{|c|}{ Dual } & \multicolumn{2}{|c|}{ Prowl } & \multicolumn{2}{|c|}{ Sancap } & \multicolumn{2}{|c|}{ Treflan } \\
\hline AYD & $\mathrm{Py}$ & AYD & $\mathrm{Py}$ & AYD & Py & AYD & Py & AYD & Py \\
\hline & $\mathbf{s}$ & & 3 & & $\$$ & & $\mathbf{s}$ & & $\$$ \\
\hline 1 & 6.50 & 1 & 5.13 & 1 & 8.63 & 1 & 9.50 & 1 & 8.59 \\
\hline 2 & 3.25 & 2 & 2.57 & 2 & 4.32 & 2 & 4.75 & 2 & 4.30 \\
\hline 3 & 2.17 & 3 & 1.71 & 3 & 2.88 & 3 & 3.17 & 3 & 2.86 \\
\hline 4 & 1.63 & 4 & 1.28 & 4 & 2.16 & 4 & 2.38 & 4 & 2.15 \\
\hline 5 & 1.30 & 5 & 1.03 & 5 & 1.73 & 5 & 1.90 & 5 & 1.72 \\
\hline 6 & 1.08 & 6 & 0.86 & 6 & 1.44 & 6 & 1.58 & 6 & 1.43 \\
\hline 7 & 0.93 & 7 & 0.73 & 7 & 1.23 & 7 & 1.36 & 7 & 1.23 \\
\hline 8 & 0.81 & 8 & 0.64 & 8 & 1.08 & 8 & 1.19 & 8 & 1.07 \\
\hline 9 & 0.72 & 9 & 0.57 & 9 & 0.96 & 9 & 1.06 & 9 & 0.95 \\
\hline 10 & 0.65 & 10 & 0.51 & 10 & 0.86 & 10 & 0.95 & 10 & 0.86 \\
\hline II & 0.59 & 11 & 0.47 & 11 & 0.78 & 11 & 0.86 & 11 & 0.78 \\
\hline 12 & 0.54 & 12 & 0.43 & 12 & 0.72 & 12 & 0.79 & 12 & 0.72 \\
\hline 13 & 0.50 & 13 & 0.39 & 13 & 0.66 & 13 & 0.73 & 13 & 0.66 \\
\hline 14 & 0.46 & 14 & 0.37 & 14 & 0.62 & 14 & 0.68 & 14 & 0.61 \\
\hline 15 & 0.43 & 15 & 0.34 & 15 & 0.58 & 15 & 0.63 & 15 & 0.67 \\
\hline 16 & 0.41 & 16 & 0.32 & 16 & 0.54 & 16 & 0.59 & 16 & 0.54 \\
\hline 17 & 0.38 & 17 & 0.30 & 17 & 0.51 & 17 & 0.56 & 17 & 0.51 \\
\hline 18 & 0.36 & & & 18 & 0.48 & 18 & 0.53 & 18 & 0.48 \\
\hline 19 & 0.34 & & & 19 & 0.45 & 19 & 0.50 & 19 & 0.45 \\
\hline 20 & 0.33 & & & 20 & 0.43 & 20 & 0.48 & 20 & 0.43 \\
\hline 21 & 0.31 & & & 21 & 0.41 & 21 & 0.45 & 21 & 0.41 \\
\hline \multirow[t]{11}{*}{22} & 0.30 & & & 22 & 0.39 & 22 & 0.43 & 22 & 0.39 \\
\hline & & & & 23 & 0.38 & 23 & 0.41 & 23 & 0.37 \\
\hline & & & & 24 & 0.96 & 24 & 0.40 & 24 & 0.36 \\
\hline & & & & 25 & 0.35 & 25 & 0.38 & 25 & 0.34 \\
\hline & & & & 26 & 0.33 & 26 & 0.37 & 26 & 0.33 \\
\hline & & & & 27 & 0.32 & 27 & 0.35 & 27 & 0.32 \\
\hline & & & & 28 & 0.31 & 28 & 0.34 & 28 & 0.31 \\
\hline & & & & 29 & 0.30 & 29 & 0.93 & 29 & 0.30 \\
\hline & & & & & & 30 & 0.32 & & \\
\hline & & & & & & 31 & 0.31 & & \\
\hline & & & & & & 32 & 0.30 & & \\
\hline
\end{tabular}

port a maximum herbicide price of $\$ 4.67 / \mathrm{lb}$ a.i. at the recommended herbicide rate). For the herbicides Prowl and Treflan, where the fixed costs are higher due to incorporation, a greater level of AYD is required than with the other herbicides. Eleven pounds of AYD for Prowl 
and Treflan are required to compensate for the fixed costs of the herbicide and application. Considering all five herbicides and given that the range of current herbicide prices is $\$ 5$ to $\$ 6 / \mathrm{lb}$, the level of AYD necessary to off set this expense requires a return of 9 to $16 \mathrm{lb} /$ acre depending on the herbicide used and its cost. This suggests that herbicide use is profitable if it results in $\geq 9 \mathrm{lb}$ of additional yield.

In addition to fluctuations in herbicide costs, the price received for cotton lint also varies. This change in revenue received determines the amount a producer can spend on weed control. Table 9 lists the costs of each additional unit of cotton received from application of herbicides. The cost of weed control does not change as AYD changes. Thus, the marginal cost of the treatment will fall as it is spread over more pounds of cotton produced. The prices were calculated by setting profit equal to zero and solving for price of cotton (Py). The price of the herbicides was set at the current retail value of the herbicide and the rate used was established as that value found to maximize profit. A cut-off level of $\$ 0.30 / \mathrm{lb}$ for the price of cotton was used to make the table manageable.

Based on results represented in Table 9 , the price of cotton should be relatively high to offset the cost of herbicide when the AYD is low. When 5 to 10 lb of AYD are reached the break-even price of cotton falls to a more realistic level of less than $\$ 1 / \mathrm{lb}$ of lint. This correlates to what is represented in Table 8 . Similarly, a relatively small increase in additional yield is needed to reach the break-even level with a price of $\$ 0.55 / \mathrm{lb}$ for cotton. Based on this price, the level of AYD required to reach this cost effective level of weed control (with constant herbicide costs) ranges from 10 to $17 \mathrm{lb} /$ acre of increased yjeld.

\section{CONCLUSIONS}

The results of this study are important when considering the current interest in, and concern for, alternative agricultural methods and Low Input Sustainable Agriculture. Results suggest that with lower herbicide application rates profits in cotton production could be increased which should reduce potential ground and surface water pollutions. Each of the five herbicides examined differ in the types of factors that affect their weed control behavior. Only Caparol and Prowl required 100\% control for maximization of profit while optimization for the other herbicides used control levels below the maximum. This suggests that, if using Dual, Sancap and Treflan, it is more profitable to plan for less than $100 \%$ control.

Higher application rates of the herbicides generally result in higher levels of control with Caparol, and Treflan. However, optimum rates were found to be less than the recommended rates on the herbicide labels suggested by the manufacturers. Caparol, for example, requires $0.75 \mathrm{lb}$ a.i./acre for economic optimization while the manuf acturer suggests 1.0 to $1.2 \mathrm{lb} /$ acre, depending on the soil type. Optimum for Sancap was 1.2 and Treflan $0.45 \mathrm{lb} /$ acre compared with the manufacturer's recommended 2.0 to $2.5 \mathrm{lb} /$ acre and 0.5 to $0.75 \mathrm{lb} /$ acre, respectively. This suggests that farmers who are following manufacturers' recommended rates of application may increase their profit by decreasing the amount of herbicide used.

Conditions present when the herbicide is applied and the crop planted are also important. Higher temperatures and/or adequate moisture at application and planting dates result in better control or higher additional yields. Control with Caparol is more effective with fine sandy clay loam (SOT-2) and fine sandy loam (SOT-1) soils than with sandy clay loam soils.

Little additional yield is necessary to justify the use of herbicides. Because the optimum expected AYD ranged from 187 to $383 \mathrm{lb} /$ acre, it is reasonable to conclude that almost any level of a weed control program using these herbicides would increase profits. The individual producer can increase profit by tailoring his weed control program to specific conditions. Remember, however, that the data set for this study did not include any form of weed control other than a single application of herbicide. Farmers who consider additional herbicide applications later in the season should consider the cost associated with the treatment as well as additional yields and expected returns from the increased weed control. This additional weed control may not be profitable as higher control levels were not profitable for some herbicides in this study.

\section{REFERENCES}

Abernathy, J.R. 1981. Estimated crop losses due to weeds with nonchemical management. p. 159-167. In D. Pimental (ed.) Handbook of pest management in agriculture. Vol. 1. CRC Press, Boca Raton, FL.

Borland International. 1987. Eureka: The solver owner's handbook, Borland International, Scotts Valley, CA.

Frans, R., and J.M. Chandler. 1989. Strategies and tactics for weed management. p. 327-361. In R.E. Frisbie et al. (ed.) Integrated pest management and cotton production. John Wiley and Sons, New York.

Hamilton, C.M. 1988. Economics of weed control in High Plains cotton production. M.S. thesis. Texas Tech Univ., Lubbock.

Holm, L.G., D.L. Plucknett, J.V. Pancho, and J.P. Herberger. 1977. The world's worst weeds: Distribution and biology. University Press of Hawaii, Honolulu.

Johnston, J. 1972. Econometric methods. 2nd ed. McGraw-Hill, St. Louis. p. 240-241.

SAS Institute. 1985. SAS users guide: Statistics. Sth ed. SAS Institute, Cary, NC.

Texas Agric. Ext. Serv. 1987. Texas crop enterprise budgets-Texas south plains district. TAES, College Station. 